\title{
The Affordable Care Act: Where Are We Now? An NCCN Roundtable
}

Presented by Christian G. Downs, JD, MHA; Liz Fowler, PhD, JD; Michael Kolodziej, MD; Lee H. Newcomer, MD, MHA; Mohammed S. Ogaily, MD; W. Thomas Purcell, MD, MBA; and John C. Winkelmann, MD; moderated by Clifford Goodman, PhD

\begin{abstract}
The Affordable Care Act (ACA) is a transformational event for health care in the United States, with multiple impacts on health care, the economy, and society. Oncologists and other health care providers are already experiencing many changes-direct and indirect, anticipated and unanticipated. A distinguished and diverse panel assembled at the NCCN 19th Annual Conference to discuss the early phase of implementation of the ACA. The roundtable touched on early successes and stumbling blocks; the impact of the ACA on contemporary oncology practice and the new risk pool facing providers, payers, and patients; and some of the current and future challenges that lie ahead for all. (J Natl Compr Canc Netw 2014;12:745-747)
\end{abstract}

Implemented just a few short months ago, the Affordable Care Act (ACA) has been heralded as a sweeping piece of necessary health care legislation by some and another feeble attempt at solving our health care crisis by others. In fact, according to the consensus of the distinguished panel assembled at the NCCN 19th Annual Conference, the ACA is currently somewhere in between. Representing the viewpoints of community and academic oncologists, administrators of managed care plans, and key members of the pharmaceutical industry, the panel explored such issues as the emerging profile of cancer patients under the new ACA, the need for temporary and permanent risk adjustment, the increased competition with participation in narrower networks, and the shifting demographics and consolidation trend.

\section{The Profile of Patients With Cancer Under the New ACA}

The panel moderator, Clifford Goodman, $\mathrm{PhD}$, Senior Vice President and Principal at The Lewin Group, Falls Church, opened the roundtable discussion with this question: Who are the patients with cancer walking through the door now under the ACA? Many members of the panel echoed the same sentiment: previously uninsured or underinsured patients. A closer look showed that the initial wave of patients enrolling in the ACA were older and sicker.

However, the consensus of the panel was that time will tell what the exact profile of these patients will be. "We are only 90 days into this, so it is just too early to know," stated Michael Kolodziej, MD, National Medical Director, Aetna. According to W. Thomas Purcell, MD, MBA, Associate Director for Clinical Services, University of Colorado Cancer Center, and Executive Medical Director, Oncology Services, University of Colorado Hospital, there does not yet appear to be a dramatic shift in the profile of the clinical cancer patient, and his institution still sees the same disease mix of patients with rare and complex cancers. However, from the perspective of Mohammed S. Ogaily, MD, Clinical Assistant Professor, Michigan State University, and Medical Director, Oakwood Center for Hematology and Oncology, University of Colorado Hospital, the pool of patients is changing, with those who have more complex issues not previously addressed by care now seeking treatment.

John J. Winkelmann, MD, private practice physician, reflected the common perspective of the panel in regard to enrolled selection, admitting that only anecdotes have emerged but few data. He added that there is some selection bias, with financial navigators and physicians often helping patients to sign up.

"The hope was that $40 \%$ of enrollment would be in the younger population, under 35 , but what we are seeing is that it is closer to $25 \%$ to $27 \%$," revealed Liz Fowler, $\mathrm{PhD}$, JD, Vice President, Global Health Policy, Johnson \& Johnson. "It is not the 25-year-olds who are signing up but the 55-year-olds," concurred Christian G. Downs, JD, MHA Executive Director, Association of Community Cancer Centers. 


\section{Assessing and Managing Risk: Current Lack of Claims Data}

With more patients potentially requiring more expensive cancer care, Dr. Goodman asked both Dr. Kolodziej and Lee H. Newcomer, MD, MHA, Senior Vice President, UnitedHealthcare, about assessing the risk pool. Both admitted that at this early point for the ACA, the necessary claims data are not available to adjust premiums, which represents a longterm challenge. Risk adjustment may take more than a year or 2, predicted Mr. Downs.

"You do what you can to manage your risk," stated Dr. Newcomer. "You start slow and learn, like with any other new process." Dr. Kolodziej concurred: "Given the uncertainty, you manage what you can manage."

According to Dr. Fowler, the Congress and the public might have to think about the adjustments that need to be made, such as reinsurance or different policies to address this risk. Three mechanisms for self-correction were built into the ACA, added Dr. Fowler: a temporary reentrance program, a temporary risk corridor program, and a permanent risk adjustment program.

\section{Early Successes and Stumbling Blocks with the ACA}

Drs. Newcomer, Kolodziej, and Ogaily agree that expanding health care coverage is inherently a good thing, and the ACA is doing that. "Better coverage for more Americans, especially with certain provisions like screening, is good for people," declared Dr. Kolodziej. "We are delighted to see the opportunity for our underinsured patients to get coverage, but the process has been slow," admitted Dr. Ogaily.

Drs. Ogaily and Newcomer cited some of the initial difficulties with the implementation of the ACA. "I hear from patients all the time about difficulties signing up," mentioned Dr. Ogaily. There were also many logistical problems with limited patient access to the system and other struggles patients have experienced, he added. Dr. Newcomer flagged the unintended consequence of making quick decisions related to the ACA, centering on having to reprogram or reverse initial decisions by the Department of Health and Human Services regarding regulations and policies, which can be expensive. "Getting to that point of stability, where decisions are made and we can move forward, will be a good thing for consumers, payers, and the government," he noted.

Dr. Goodman also asked the panel what might be missing from the ACA. According to Dr. Winkelmann, oncology organizations such as ASCO would like to see more explicit provisions in the ACA that patients who enter clinical trials will not suffer financial penalties.

Dr. Newcomer noted that the lack of a medical necessity clause is an issue for him. For instance, some of the multiple options listed in guidelines are less expensive than others, but they yield the same end results, often with the same toxicities. The inability to consider the most cost-effective option under both Medicare and the ACA concerns him.

\section{Narrow Networks, More Competition}

"Much of the ACA is designed to promote and incentivize certain care delivery and payment models," stated Dr. Goodman. He then asked whether the panel was seeing any movement in the organization of cancer care and payment of care in intended or unintended ways.

"The participation in the narrow network is the underpinning of more competition," stated Dr. Purcell, and Dr. Ogaily agreed. Patients may be unable to come to an academic cancer center for care if they are in a narrow network that excludes the center and does not cover services provided there. In addition, the level of financial counseling for every patient has been increased at his cancer center, declared Dr. Purcell. "What worries me is that the narrow network is defined by cost, and the decision is made purely on cost, and the quality aspect may be an issue," he added.

\section{Shifting Demographics and the Consolidation Trend}

Asked whether the ACA is responsible for the trend toward consolidation of practice settings, the panel said not completely. According to Mr. Downs, "consolidation [of hospitals and physician practices by other hospitals or physician group practices] is more an artifact of the MMA [Medicare Prescription Drug, Improvement, and Modernization Act] than of the ACA." Dr. Fowler agreed, adding "although the trend was already in place, the ACA has accel- 


\section{Meet the Panelists}

Clifford Goodman, PhD, moderator: Senior Vice President and Principal at The Lewin Group, a health care policy consulting firm based in Falls Church, Virginia. With 30 years of experience in health care evaluation, Dr. Goodman directs studies and projects for international government agencies, pharmaceutical companies, medical institutions, and patient advocacy groups.

Christian G. Downs, JD, MHA: Executive Director, Association of Community Cancer Centers (ACCC). Mr. Downs brings more than 20 years of experience working with providers and cancer organizations on national policy and educational programming. Before joining the ACCC, Mr. Downs worked in the public policy department of ASCO.

Liz Fowler, PhD, JD: Vice President, Global Health Policy, Johnson \& Johnson. Dr. Fowler joined Johnson \& Johnson from the White House, where she served as Special Assistant to the President for Health Care and Economic Policy at the National Economic Council and played a role in developing the Senate version of health reform.

Michael Kolodziej, MD: National Medical Director, Oncology Strategy, Office of the Chief Medical Officer, Aetna. Before joining Aetna, Dr. Kolodziej served as Medical Director for Oncology Services for US Oncology (USON), helping to direct the implementation of the USON clinical pathways initiative.

Lee H. Newcomer, MD, MHA: Senior Vice President, UnitedHealthcare, with strategic responsibility for oncology, genetics, and women's health. Dr. Newcomer held a number of positions at the United Health Group, including Chief Medical Officer, and emphasized the development of performance measures and incentives to improve clinical care.

Mohammed S. Ogaily, MD: Clinical Assistant Professor, Michigan State University, and Medical Director, Oakwood Center for Hematology and Oncology, Detroit, Michigan. Board-certified in internal medicine and oncology, Dr. Ogaily is President of the Michigan Society of Hematology \& Oncology.

W. Thomas Purcell, MD, MBA: Associate Director for Clinical Services, University of Colorado Cancer Center, and Executive Medical Director, Oncology Services, University of Colorado Hospital. Prior to joining the University of Colorado, Dr. Purcell was Director of the Billings Clinic Cancer Center, Billings, Montana, for more than 7 years.

John C. Winkelmann, MD: Private Practice Physician, Oncology Hematology Care, Cincinnati, Ohio. Specializing in hematologic malignancies and boardcertified in internal medicine and hematology, Dr. Winkelmann is a member of the American Society of Hematology, where he is currently serving as Councillor on the Executive Committee. erated this trend to mergers, acquisition, and consolidation." Mr. Downs added that there are different requirements and regulations in hospital and group practice settings.

Furthermore, Dr. Winkelmann emphasized that the workforce demands in oncology are not all attributable to the ACA but rather to demographic shifts in the population. Dr. Ogaily agreed about the changing demographics of oncology practices. For him, the concern is that large practices are located in metropolitan areas, and so outlying and rural areas will not be as well covered with the loss of many community practices.

\section{Moving From Rewarding Volume to Rewarding Value}

Although admittedly a rough transition, "The intent of the ACA was to move us from a fee-for-service system that rewards volume to a system that rewards value and looks at outcomes and quality," explained Dr. Fowler.

Dr. Purcell mentioned the difficulty of thinking outside the box when we are locked into the current payment scheme, and Dr. Newcomer agreed that a whole new approach is needed. "Financial incentives keep us locked into old models," he added. Physicians can direct the care and create the treatment plan, he said, but many health care professionals (such as advance practice nurses, nurse practitioners, and physician assistants) can provide that care. "If we rethink it, we can solve the problem," proposed Dr. Newcomer.

Integrated care, payment reform, increased focus on value, and awareness of quality metrics are the keys to the success of the implementation of the ACA, according to the general consensus of the panel.

\section{Closing Comments: Grading the ACA So Far}

Dr. Goodman concluded the discussion by asking the panel to grade the ACA so far on a scale of 0 to 10 , with 0 being a flop and 10 being the most effective program ever. The average score of the 7 panel members was a 5. Although Dr. Fowler scored the current ACA a 5 or a 6 , she stated that once it is fixed, it should rank between an 8 and a 9. So stay tuned. 